Malaysian Journal of Social Sciences and Humanities (MJSSH)

Volume 4, Issue 7, November 2019

e-ISSN : 2504-8562

Journal home page:

www.msocialsciences.com

\title{
A Pilot Study of the Relationship Between Parenting Style and Academic Procrastination Among Final Year Students of Faculty of Human Ecology, Universiti Putra Malaysia (UPM)
}

\author{
Fasya Sulaiman', Mohammad Mujaheed Hassan' \\ ${ }_{1}^{1}$ Department of Social and Development Science, Faculty of Human Ecology, Universiti Putra Malaysia (UPM) \\ Correspondence: Mohammad Mujaheed Hassan (mujaheed@upm.edu.my)
}

\begin{abstract}
$\overline{\text { Academic procrastination is a behaviour which can be defined as putting off, delay, prolong, defer, }}$ stall, or postpone in performing tasks related to the academic. Academic procrastination is not a new phenomenon but it is a common behaviour especially among students as previous research has found that approximately $75 \%$ of students consider themselves as procrastinators. This issue is very much related to the "Student Syndrome" where student only starts to make themselves work in completing the task instantly right before the due date and leaving them with a very short period of time to complete it. There were many previous researchers that had investigated the factors that causing academic procrastination and one of the most common factors are parenting style. However, the pattern of the previous results was inconsistent. Therefore, the purpose of this study is to investigate in deep on the relationship between the motivational aspects of parenting style to academic procrastination with focusing among the undergraduate students who are in their final year from Faculty of Human Ecology, Universiti Putra Malaysia. The research design of this study is a quantitative research and for that reason, a set of questionnaire was distributed to 148 respondents. Result shows that $52.7 \%$ of the final year students perceived at high level of academic procrastination. Apart from that, the result also shows that there is no significant relationship between gender and parenting styles to academic procrastination. As a conclusion, academic procrastination is a common behaviour among final year students. However, parenting styles does not affecting academic procrastination due to the students' age which can be categorised as early adulthood which at this age, parenting style factors does not give an impact on academic procrastination.
\end{abstract}

Keywords: procrastination, academic, parenting style, students

\section{Introduction}

Procrastination is a behaviour which can be defined as putting off, delay, prolong, defer, stall, or postpone performing duties (Zakeri et al, 2013) such as preparing for exams and delaying homework sometimes or constantly (Rothblum, Solomon and Murakami, 1986) as mentioned in an article by Kandemir (2014) is a common behaviour. In a book titled Procrastination and Task Avoidance by Ferrari, Johnson, and McCown (1995) also stated that procrastination is purely a modern phenomenon. However, according to William James, procrastination is not a new phenomenon as he had identified that psychological cost of procrastination about 120 years ago (Klassen, Krawchuk \& Rajani, 2008). Due to researcher's interest on the topic, a lot of research has been done on procrastination from 
different parts of the world. However, "much has yet to be learned about the causes of procrastination"' (Steel, 2007, p. 65).

From the global aspects, Potts (1987) in Steel (2007) stated that approximately $75 \%$ of students consider themselves as procrastinators which means more than $50 \%$ of students procrastinate in academic tasks. This can be proven by a study done by Hussain and Sultan (2010) on analysis of procrastination among university students in Pakistan. The results shows that $87 \%$ of the students delay in preparing and submitting their assignments, 68\% delaying in preparing and submitting for presentations, and $62 \%$ delaying in preparing for the examinations. However in a local context, the tendencies to procrastinate among students are also higher. This was proven through a study done by Bakar and Khan (2016) among university students in Malaysia which found that $67 \%$ are procrastinators, $21 \%$ are not serious procrastinators, and another $12 \%$ are serious procrastinators. Therefore, this study is designed to identify the relationship between parenting style and academic procrastination among students. The effect of some demographic variable such as gender on academic procrastination will also be examined.

\section{Academic Procrastination}

For the past few years, procrastination has been a topic of interest among some researchers as the behaviour is very common across different areas and fields. This is because majority every individual procrastinates in performing their responsibilities and tasks throughout their life. Therefore, different perspectives on procrastination occur making the definitions varies. According to Solomon and Rothblum (1984), they defined procrastination as an action of needlessly delaying tasks until the subject reach a point where they would be discomfort. Shah (2000) in Hussain and Sultan (2010) defined procrastination as an attitude or behaviour which he described as an "indecisive state lacking in will power and vitality to do a work" (2010, pg. 1897). In general, procrastination is a behaviour where the individual lack of self-control and strength in doing their work.

According to other researchers (Ziesat, Rosenthal, \& White, 1978), academic procrastination to be said as a behaviour where academic activities are intentionally postponed from time to time whether in the beginning or during completion of that specific task (Rabin, Fogel, \& Nutter-Upham, 2011). In other words, academic procrastination appears to be a behaviour where students purposely ignoring their responsibilities in academic. The examples of procrastinating academic tasks are postponing the preparation and submission of assignments, presentations, projects and examination preparation (Hussain \& Sultan, 2010). Besides that, other examples postponement on academic tasks by other researchers are preparing term papers, reading weekly assignments and studying the lessons a day before the exams (Moonaghi \& Beydokhti, 2017; Rabin, Fogel, \& Nutter-Upham, 2011).

Have we all wonder what are the factors that causes this type of behaviour to exists until it has been known as a common practice especially among adults and the university students? There were many previous researches which have discussed on the factors that contribute to procrastination specifically in academic. One of the researchers (Lay, 2004) in a research done by Rabin et al. (2011) have proposed that there are various possible predictors in procrastination which are in terms of cognitive, emotional, as well as personality variables. Low self-esteem, low academic self-efficacy, fear of failure and false perceptions on the time required and available in completing the tasks are always associated to cognitive aspects. However, in a research which was carried out by Stuart (2013), she conclude that although the African American and Hispanic students in her research did not shows high levels of fear of failure correlates with procrastination, but at the end of semester the students received significantly lower GPA scores.

The second possible factor to procrastination which was highlighted by Rabin et al. (2011) in her study was emotional functioning. Generally, emotional functioning referring to one's ability in coping with life events and respond accordingly. In Rabin et al. (2011) stated that other studies (Stoeber \& Joormann, 2001; Van Eerde, 2003) found that anxiety, depression and worry often associated with procrastination. At times there are students who procrastinate due to fear of certain courses or subjects 
which may be hard for them to understand. For example, in a research done by Onwuegbuzie (2004) in studying the academic procrastination and statistic anxiety, found that graduate students who is taking statistics course tend to procrastinate which then resulting to multidimensional statistics anxiety such as interpretation anxiety and also test and class anxiety.

The third possible factor to procrastination highlighted by Rabin et al. (2011) is personality variables. Aydogan (2008) in Kagan et al. (2010) explained that apart from time management skills and weak self-efficacy, other personal characteristics such as responsibility and perfectionism are also associated with procrastination. According to a study done by Jadidi et al. (2011) on perfectionism and academic procrastination among 200 students from universities in the city of Tehran, the results shows that there was a positive correlation between perfectionism and academic procrastination. The outcome form the study means that students with high level of perfectionism tend to be more procrastinate in academic. From my understanding on the relationship between these two variables is that students who wish to achieve highest standard in completing that particular task given tend to have other tasks pending which need to be completed soon as they have the need to make sure that each task which they currently doing to be perfect.

When talking about any kind of behaviours of human being there will always be the reasons for the behaviours to happen and effects from doing it. In academic procrastination, there are many possible effects can appear as the consequences. In a research done by Hussain and Sultan (2010) they have discussed on several effects of academic procrastination which Sirois \& Pychyl (2002) stated that academic procrastination can cause unhealthy habits that can effect health such as sleep unhealthy sleeping habit as well as diet and exercise habit (Hussain \& Sultan, 2010). Apart from causing diseases such as digestive ailments, cold and flu, Adkins and Parker (1996) explained that this type of procrastination also may cause the individuals to involve in other bad habits such as smoking and drinking (Hussain \& Sultan, 2010). However, Goode (2008) in Hussain and Sultan (2010) had mentioned that procrastination can causes plagiarism. This statement can be supported by a study done by Siaputra (2013) who found out that out of the five predictors of plagiarism which are procrastination, performance, personality, perfectionism, and achievement motivation, procrastination was the best predictor as the result shows that procrastination produced positive and significant correlation with plagiarism. In short, we could say that academic procrastination brings various negative effects to the health physically and mentally as well as the ability of people to achieve their objectives.

\section{Parenting Style}

In the process of socialization, Ladd and Pettit (2002) in Spera (2005) define socialization as a child manner which is required in order to successfully adapt within a family or culture through education, training, observation, experience, acquiring skills, motives, attitudes as well as behaviours. In order for this process to happen among the children, parents are the most important influences on their children's behaviour, and this happened due to different parenting styles and practices. Maccoby and Martin (1983) in Spera (2005) stated that in previous studies, researchers were often used the terms of parenting styles and parenting practices alternatively.

However, parenting styles and parenting practices brings different meaning. The definition of parenting practices is adapted from Darling and Steinberg (1993) in Spera (2005, pp. 127) as the "specific behaviours that parents use to socialize their children". The definition is almost the same as what have been defined by Pugliese and Tinsley (2007) which they describe parenting practices as the specific behaviours that parents does such as actions taken by parents to facilitate physical activity (Jago et. al, 2011). In parenting practices, for example, parents might be applying a certain practice such as doing school work together with their children in order in order to socialize their children to succeed in school (Spera, 2005).

Baumrind (1971) in Jago et. al (2011) defined parenting style as how parent communicates with their children but on the other hand, Darling and Steinberg (1993) define parenting style as "the emotional 
climate in which parents raise their children" (Spera, 2005, pp. 127). According to Cobb-Clark et al. (2017), she explained in her article that parenting styles can be differentiate by two categories which are demandingness (control) and responsiveness (warmth). These dimensions are very useful in explaining the different types of the parenting styles. According to Baumrind (1991), responsiveness is referring to which parents be attuned, supportive, and acquiescent to their children's needs and demands to intentionally foster individuality, self-regulation and self-assertion while demandingness refers to which parents applies maturity demands, supervision, disciplinary efforts and willingly confront disobeyed child in order to make their children become integrated to the whole family.

Baumrind (1971) in Alkharusi et al. (2011) have identified three major parenting styles which are authoritative, authoritarian, and permissive. Parents with authoritative style are both responsive and demanding. Apart from provide love and warmth, Baumrind (1978) in Baumrind (1991) also explained that authoritative parents always support their children's interest by providing the required resources in order to allow the children to be success in their area of interest. However, authoritative parents have high maturity demands which mean they have high expectations in terms of the children's achievement. Apart from that, this type of parenting demand for their children to utilize reasoning which means every behaviour would need explanation, and they also encourage them to be independent (Spera, 2005). To sum up, parents with authoritative style are responsive which means they support their children's interest by providing the needs or resources required for their exploration however, the children would need to successfully pursue their interest as demanded. Although they are demanding, but they communicate with their children by providing them with rationale for the demand.

The second type of parenting would be authoritarian style. Differ from authoritative, authoritarian is characterized by high demand but low responsiveness (Baumrind, 1991). Baumrind (1978) in Spera (2005) explained that this kind of parenting style are tend to be inconsiderate as they have maturity demands for their children but yet they did not give feedback or give some support for their children in order to making the expectations come true. Usually, the parents with authoritarian style express their demands and expectation through rules and orders, and not stating the rationale of the rules when socializing with their children. This made authoritarian parents to be labelled as strict, anticipating for obedience behaviour, and use the power that they have when their children misbehave (Baumrind, 1991). In short, parents with authoritarian style have high demand on their children which they expect them to be like how they want however they do not communicate with their children on the needs, giving support, or explaining the rationale behind the restrictions that have set up in order for the children to follow and this shows the low responsiveness.

The third parenting style which have been identified by Baumrind (1978) in Spera (2005) is permissive parenting style which he suggested that it is categorized by moderately high in responsiveness and low demands. Moderate responsiveness here means that some parents can be high responsive and some can be low responsive toward the needs of their children. Although they are warmth, however they are usually unconcerned, as they seldom put high expectation on the children's maturity and behaviour. The two-factor approach, which are demandingness and responsiveness also had causes for and extension of Baumrind's parenting styles which is "disengaged" as the fourth parenting style (Cobb-Clark et al. (2017). Wake et al. (2007) in Cobb-Clark et al. (2017) stated that disengaged parenting is categorised as low in both demandingness and responsiveness which always been relate to the children's impulsivity, behavioural and emotional problems, school dropout, substance abuse, as well as delinquency.

\section{Relationship Between Parenting Style And Academic Procrastination}

It is indeed a part of our life where parents play an important role in the development of their children. Although if there are some people who may not think of that, some researchers (Brown, Mounts, Lamborn, \& Steinberg, 1993) in Pychyl et al. (2002) also had previously stated that parents do play a significant role in their child's development. Generally, child development means the changing process of physical, language, thought as well as the emotions from the birth to adulthood and the guidance from parents are crucial throughout the process. Heaven and Ciarrochi (2008) in Lee (2013) states that 
apart from parent-child attachment and interaction, parenting styles are the key role in developing the children's personality and behaviours.

Different parenting styles may result in different outcomes from their children. Outcomes from the children are closely related to behaviour and procrastination can be one of the behaviour and is common in the societies (Zakeri et al., 2013). Zakeri et al. (2013) who investigate the relationship between parenting styles and academic procrastination among 395 students of Shiraz Univeristy in Iran which the result revealed that there was a significant correlation between parenting styles and academic procrastination. However, the model of parenting style used by Zakeri et al. (2013) is Parenting Scale by Steinberg (2005) which the subscales are acceptance-involvement, psychological autonomygranting and strictness-supervision.

However, other researchers mostly were using the Baumrind (1978) parenting styles which the subscales are authoritative, authoritarian and permissive style (Spera, 2005). Based on a study done by Loa (2012) in Indonesia, it was found that there were no correlation between academic procrastination with authoritarian and permissive style but there was a positive correlation with authoritative style. According to a study done by Javady and Mahmoudi (2015) on academic procrastination and its relationship with perceived parenting styles and fear of success among 331 subjects, they found out that authoritarian and permissive style are high in prediction of procrastination variable.

Similarly, Mahasneh et. al. (2016) who investigates the relationship between academic procrastination and parenting styles among Jordanian undergraduate university students shows a positive and significant relationship between academic procrastination and parenting styles. Out of the three parenting styles, authoritarian parenting style shows the highest variance percentage of $12.9 \%$ in student's procrastination. This result indirectly had proven the study carried out by Pychyl et. al. (2001) on parenting and procrastination.

Here, we can conclude that from the previous research, permissive parenting style is positively correlated to academic procrastination. This is because when the parents are less demanding for their children such as do not put high expectation on the children's achievement, therefore the children tend to procrastinate in academic which this may lead to poor academic achievement.

\section{Definition Of Terminologies}

\section{Academic Procrastination}

Conceptual Definition: Procrastination was defined as "the act of needlessly delaying tasks to the point of experiencing subjective discomfort" (Solomon \& Rothblum, 1984, p.503) such as completing homework, and getting ready for examinations at the last minute (Kagan et al., 2010).

Operational Definition: Academic procrastination can be assessed by using Procrastination Assessment Student Scale (Solomon \& Rothblum, 1994). which it helps in assessing the students procrastination behaviour in academic tasks. The higher the total score shows the higher level of procrastination behaviour.

\section{Parenting Style}

Conceptual definition: According to Darling and Steinberg (1993), parenting styles is referring to the formation of attitudes which are implement by parents towards their children which the parent's behaviours such as goal-directed behaviours (parenting practices) or non-goal-directed behaviours (gestures, voice tone, or spontaneous emotion).

Operational definition: Parenting styles can be assessed by the student's perceptions on their parents' specific behaviours when interacting with them in terms of social, educational and personal aspects in 
order to see whether their parents are permissive, authoritative, or authoritarian style. This can be done by using the Parental Authority Questionnaire (PAQ) with the total of 30 items.

\section{Research Objective}

i. To identify the level of academic procrastination among final year students in Faculty of Human Ecology, Universiti Putra Malaysia;

ii. To identify the relationship between gender differences and academic procrastination among final year students in Faculty of Human Ecology, Universiti Putra Malaysia;

iii. To identify the relationship between parenting styles and academic procrastination among final year students in Faculty of Human Ecology, Universiti Putra Malaysia;

iv. To identify the relationship between authoritative parenting style and academic procrastination among final year students;

v. To identify the relationship between authoritarian parenting style and academic procrastination among final year students;

vi. To identify the relationship between permissive parenting style and academic procrastination among final year students.

\section{Research Methodology}

\section{Research Design}

This pilot study are using purposive quantitative research study which using computational, statistical or mathematical tools in order to investigate the current phenomena on the selected topic of interest.

\section{Population and Sample}

Faculty of Human Ecology, Universiti Putra Malaysia in Serdang, Selangor was selected as location for this pilot study. The main focus group of this pilot study is a final year students of Faculty of Human Ecology. A final year's student was chosen as a respondent because the tendency level of seniors to procrastinate is higher compare to the freshmen, sophomores or other juniors. As proven by McCown and Roberts (1994) in Sirin (2011), who studied on the procrastination among undergraduates had found that $31 \%$ of the seniors have been reported to have thought academic procrastination as a source of stress which the percentage is higher than juniors, sophomores, and freshmen with the percentage of $27 \%, 22 \%$ and $19 \%$ respectively. Generally there are five (5) Bachelor Programme offers by Faculty of Human Ecology which are i) Bachelor Science of Human Development (HD), ii) Human Development and Management (HDM), iii) Human Development and Information Technology (HDIT), iv) Consumer Studies (BPG), and v) Music. There are total of 237 final year students in Faculty of Human Ecology for 2018/2019 session. Based on table for research sample size by Krejcie and Morgan (1970), 148 students are randomly selected within the final year populations.

\section{Data Collection}

In this pilot study, data was collected by using a set of questionnaire. Respondents are required to answer all the questions provided in the questionnaire. The questionnaire consists of three (3) sections which are sections A, B and C. Section A consists of respondents' background or personal information which includes gender, age, race and CGPA. Section B consists of Parental Authority Questionnaire (PAQ) which to measure the parental authority or disciplinary practices from the respondents' point of view as the child. Lastly, Section C consists of Procrastination Assessment for Students Scale (PASS) that used to measure the level of academic procrastination among the students. 


\section{Research Instrument}

\section{Parental Authority Questionnaire (PAQ) Instrument}

The Parental Authority Questionnaire (PAQ) was designed by Buri (1991) in order to measure Baumrind's (1971) parenting styles which the styles are authoritarian, authoritative, and permissive. The questionnaire consists of 30 items that is grouped into three (3) main subscales which each of the subscale consists of 10 items (Table 1).

A Likert Scale of 5 point were used to measure PAQ which are $1=$ strongly disagree, $2=$ disagree, $3=$ neither agree nor disagree, $4=$ agree, $5=$ strongly disagree. All 30 items of the scale will be answered by the respondents on their perspective towards their mother parenting practices, and the same 30 items also will be answered by respondents on their perspective towards their father parenting practices. Based on the study done by Mahasneh et al. (2016), the authors had obtained the reliability score from their pilot test and they obtained the Cronbach's alpha score of 0.77 for authoritativeness, 0.79 for authoritarianism, and 0.73 for permissiveness. This shows that the scale is highly reliable.

Table 1: Question Numbers of Each Parenting Style

\begin{tabular}{cc}
\hline Parenting Styles & Question Number \\
\hline Permissive & $1,6,10,13,14,17,19,21,24,28$ \\
Authoritarian & $2,3,7,9,12,16,18,25,26,29$ \\
Authoritative & $4,5,8,11,15,20,22,23,27,30$ \\
\hline
\end{tabular}

Ribeiro (2009) also further explained that the reason for why PAQ does not include 10 questions for neglectful parenting style specifically is because out of 10 questions regarding permissive parenting style, there are few questions can be said are related to indulgent parenting which seven questions related to indulgent parenting while the other three related to neglectful parenting.

\section{Procrastination Assessment Scale for Students (PASS) Instrument}

The Procrastination Assessment Scale for Student (PASS) was developed by Solomon and Rothblum (1994) originally consists of two parts. The first part of the scale is to evaluate the commonness of procrastination among students in six academic areas which are in writing term paper, studying for an exam, keeping up with reading assignments, performing administrative tasks, attending meetings, and performing school activities in general. As for the second part of the scale, it is for identifying the potential reasons for procrastination the tasks. However for this study, only the first part of the scale will be adopted.

Originally, for the first part of the scale, each academic area consists of three different rating scales which first indicating the degree to which they procrastinate on the task $(1=$ Never procrastinate, $2=$ Almost never, $3=$ Sometimes, $4=$ Nearly always, $5=$ Always procrastinate). Secondly is on whether procrastination on the task is a problem $(1=$ Not at all a problem, $2=$ Almost never, $3=$ Sometimes, 4 $=$ Nearly always, $5=$ Always a problem) and lastly to know whether students want to decrease the tendency to procrastinate on the task.

In this research study, only the first two questions will be include and both will be sum for each task with scores ranging from 2 to 10 as well as across the 6 areas with total scored ranging from 12 to 60 which make the total no of items which will be use is 12 items on procrastination (Park, 2008). The third question which on to know whether students want to decrease the tendency to procrastinate on the task will not be used as the question is not relevant for this study. Some terms such as "term paper" and "professors" in this instrument will be change to "assignment" and "lecturers" respectively as these words are commonly used among Malaysian students. 


\section{Data Analysis}

The data analysed by using Statistical Package for Social Science (SPSS for windows). For section A of the questionnaire, a descriptive statistics will be used in order to describe and summarize the data of the basic features such as gender, age, race and CGPA. By using descriptive statistics, besides of helping in assessing the frequency, percentage, mean, minimum and maximum value of the data for section $\mathrm{A}$, it is also will be used to assess the above information for sections $\mathrm{B}$, and $\mathrm{C}$. In order to answer objective 1, the academic procrastination variables has been divided into three groups which are low, moderate and high level in order to identify the level of academic procrastination among the final year students.

T-test analysis used to identify the significant relationship between gender differences and academic procrastination in order to indicates whether or not the difference between the two groups of gender's average most likely to reflect the academic procrastination behaviour. Beside T-test, Chi-square also will be use to go into deeper to see the relationship between the different level of academic procrastination (low, moderate, and high) among the two gender groups (male and female). Therefore, T-test and Chi-square analysis are relevant to use to achieve Objective 2.

On the other hand, the analysis on correlation in this study would require Pearson's Correlation test in order to analyse each of the hypothesis in this study for an explanation whether there is a positive or negative significant relationship between the independent variables and the dependent variable which are parenting style and academic procrastination. Cross Tabulation used to identify the relationship between the different level of academic procrastination (low, moderate, and high) with parenting styles (authoritative, authoritarian, and permissive).

Table 2: Summary of Statistical Test used for the Pilot Study

\begin{tabular}{lc}
\multicolumn{1}{c}{ Statistical Test } & Part/Objective \\
\hline Descriptive Analysis & Part A, B, C and Objective 1 \\
T-test Analysis & Objective 2 \\
Chi-Square Analysis & Objective 3 \\
Pearson Correlation Analysis \\
Cross Tabulation Analysis
\end{tabular}

\section{Research Limitation}

This pilot study focuses on the parenting style on academic procrastination among the undergraduates of Faculty of Human Ecology, Universiti Putra Malaysia, who is currently in their final years. Since this study will only be limited to only one faculty in the Universiti Putra Malaysia, this may not reflect the overall academic procrastination behaviour of undergraduate students as a whole. Furthermore, as this study will be using self-reporting instruments, respondents may respond to the questionnaire about themselves positively in order to avoid undesirability which this may skew the data reporting.

\section{Finding \& Analysis}

\section{Reliability Test}

A reliability test consisting of 148 respondents which all were final year students of Faculty of Human Ecology, Universiti Putra Malaysia have been carried out in order to determine the reliability of all instruments used which are Parental Authority Questionnaire (PAQ) and Procrastination Assessment Scale for Students (PASS). The Cronbach's Alpha of each instrument is shown as in the Table 3 and Table 4. 
Table 3: Cronbach Alpha for Parental Authority Questionnaire (PAQ)

\begin{tabular}{lcc}
\hline & No. of items & Cronbach's Alpha \\
\hline Authoritative & 20 & Actual $(\mathbf{N}=\mathbf{1 4 8})$ \\
Authoritarian & 20 & 0.878 \\
Permissive & 20 & 0.799 \\
\hline
\end{tabular}

Table 4: Cronbach Alpha for Procrastination Assessment Scale for Students (PASS)

\begin{tabular}{cc}
\hline & Cronbach's Alpha \\
\hline No. of items & Actual $(\mathrm{N}=148)$ \\
12 items & 0.817 \\
\hline
\end{tabular}

\section{Analysis on Personal Information of Respondents}

Based on the data, it shows that majority number of respondents for this study were female with 127 $(85.80 \%)$ number of students while another $21(14.20 \%)$ were male students. In overall, the age of the final year students of Faculty of Human Ecology range from 22 to 27 years old. Based on the diagram, it shows that majority of the respondents are 23 years old with a total of $72(48.60 \%)$ students. Followed by respondents of age 24 years old with a total of $41(27.70 \%)$ students, $14(9.50 \%)$ students are at the age of 26 years old, $10(6.80 \%)$ students are at the age of 25 years old, $9(6.1 \%)$ students are at the age of 22 and lastly only $2(1.40 \%)$ students are 27 years old. Majority of the respondents are Malay with a total number of $127(85.80 \%)$ students, followed by $10(6.80 \%)$ students are Indian, 8 $(5.40 \%)$ students are others, and lastly $3(2.0 \%)$ students are Chinese. Students who answered "Others" as their race are consists students of Iban, Bidayuh, Orang Asli and Chindian. Based on the data, it shows that majority of the respondents are in the Second Class Upper Honours $(3.000-3.749)$ with the total of $121(81.80 \%)$ students, followed by Second Class Lower Honours $(2.250-2.999)$ with the total of $15(10.10 \%)$ students and lastly, $12(8.10 \%)$ students are in the First Class Honours $(3.750-$ 4.000).

Table 5: The tabulations of Respondents Personal Information

\begin{tabular}{lcc}
\hline Variable & n & \% \\
\hline Gender & 21 & 14.20 \\
Male & 127 & 85.80 \\
Female & &
\end{tabular}

Age

$\begin{array}{ccc}22 & 9 & 6.10 \\ 23 & 72 & 48.60 \\ 24 & 41 & 27.70 \\ 25 & 10 & 6.80 \\ 26 & 14 & 9.50 \\ 27 & 2 & 1.40\end{array}$

Race

Malay $\quad 127$

85.80

$\begin{array}{lll}\text { Chinese } & 3 & 2.0\end{array}$

Indian $\quad 10 \quad 6.80$

$\begin{array}{lll}\text { Others } & 8 & 5.40\end{array}$

Academic Performance (CGPA) 
First Class Honours

\section{Analysis on Level of Academic Procrastination among Respondents}

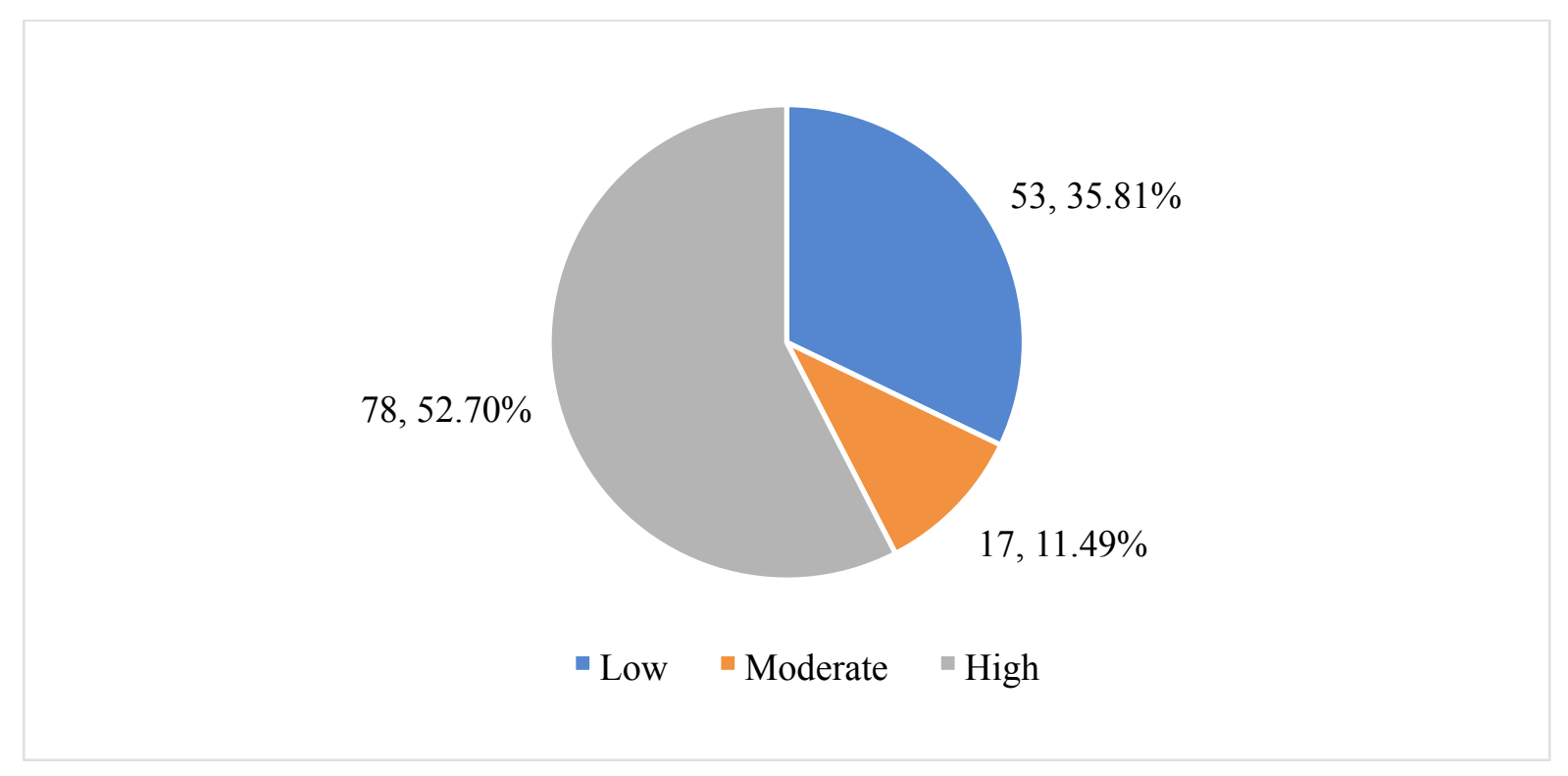

Diagram 1: Level of Academic Procrastination among Respondents

Diagram 1 shows the level of academic procrastination among respondents who are the final year students of Faculty of Human Ecology, Universiti Putra Malaysia. Majority of 78 (52.70\%) students have a high level of procrastination in academic, 53 (35.81\%) students are at a low level of procrastination and only $17(11.49 \%)$ students are at moderate level of academic procrastination.

Table 6: Mean Score of Likert Scale to Measure the Level of Academic Procrastination

$(\mathrm{N}=148)$

\begin{tabular}{lc}
\hline \multicolumn{1}{c}{ Likert Scale } & Level of Academic Procrastination \\
\hline Mean score of $1.00-2.99$ & Low \\
Mean score of 3.00 & Moderate \\
Mean score of $3.01-5.00$ & High \\
\hline
\end{tabular}

Table 7: Mean Score of Procrastination in Academic Tasks ( $N=148)$

\begin{tabular}{lcc}
\multicolumn{1}{c}{ Academic Tasks } & Mean & Std. Deviation \\
\hline Studying for exams & 3.3446 & 0.84687 \\
Writing an assignment/Term Paper/Project & 3.2432 & 0.72489 \\
Keeping up with weekly assignment & 3.2061 & 0.83489 \\
University/Faculty/College activities in general & 3.1419 & 0.88071 \\
Academic administrative tasks & 2.7973 & 1.01156 \\
Attendance tasks & 2.7905 & 0.94942 \\
\hline
\end{tabular}

Table 7 shows the mean score of each procrastination in different academic task. Based on the table above, it shows that studying for exams have the highest mean score of 3.3446, followed by writing an assignment/term paper/project with mean score of 3.2432, 3.2061 for keeping up with weekly assignment, 3.1419 for University/Faculty/College activities in general, and 2.7973 for academic 
administrative tasks. Last but not least, procrastination in attendance tasks shows the lowest mean score of 2.7905 .

\section{Analysis on the Relationship between Gender Differences and Academic Procrastination among Respondents}

Chi-square analysis was conducted in order to identify the relationship between gender differences and level of academic procrastination among the final students of Faculty of Human Ecology, Universiti Putra Malaysia. The hypothesis of the test is as follow, Hal: There is significant relationship between gender and academic procrastination among final year students.

Table 8: Chi-square Analysis between Gender Differences and Level of Academic Procrastination $(\mathrm{N}=148)$

\begin{tabular}{lcccc}
\hline Variable & \multicolumn{2}{c}{ Gender (n (\%)) } & \multirow{2}{*}{$\boldsymbol{x}^{2}$} & \multirow{2}{*}{ p } \\
\cline { 2 - 3 } & \multicolumn{1}{c}{ Male } & Female & & 2.949 \\
Level of Academic Procrastination & & & 0.229 \\
$\quad$ Low & $11(20.80 \%)$ & $42(79.20 \%)$ & & \\
$\quad$ Moderate & $2(11.80 \%)$ & $15(88.20 \%)$ & & \\
$\quad$ High & $8(10.30 \%)$ & $70(89.70 \%)$ & & \\
Total & $21(14.20 \%)$ & $127(85.80 \%)$ & & \\
\hline
\end{tabular}

Based on Table 8, it shows that there is no significant relationship $\left(x^{2}=2.949, p=0.229\right)$ between gender differences and level of academic procrastination among final year students of Faculty of Human Ecology. Therefore, the hypothesis is rejected. Based on the Table 8, although there are no significant relationship between gender differences and level of academic procrastination, data shows that female students have a high level of academic procrastination of $55.12 \%(70 / 127)$ while male students have a low level of academic procrastination of $52.38 \%(11 / 21)$ respectively.

\section{Analysis on the Relationship between Parenting Style and Academic Procrastination among Respondents}

Pearson Correlation analysis was conducted in order to identify the relationship between parenting style and academic procrastination among the final students of Faculty of Human Ecology, Universiti Putra Malaysia. Based on Table 10, it shows that there is no significant relationship $(r=.117, \mathrm{p}=.158)$ between parenting style and academic procrastination among final year students of Faculty of Human Ecology.

Table 9: Rule of Thumb for the Size of a Correlation Coefficient

\begin{tabular}{cc}
\hline Size of the correlation & Interpretation \\
\hline \pm 0.90 to \pm 1.00 & Very high positive / negative correlation \\
\pm 0.70 to \pm 0.90 & High positive / negative correlation \\
\pm 0.50 to \pm 0.70 & Moderate positive / negative correlation \\
\pm 0.30 to \pm 0.50 & Low positive / negative correlation \\
\pm 0.00 to \pm 0.30 & Negligible correlation \\
\hline
\end{tabular}

Table 10: Pearson Correlation Analysis between Parenting Style and Academic Procrastination $(\mathrm{N}=148)$

\begin{tabular}{lcc}
\hline Variable & \multicolumn{2}{c}{ Academic Procrastination } \\
\cline { 2 - 3 } & $\boldsymbol{r}$ & $\mathbf{p}$ \\
\hline Parenting Style & 0.117 & 0.158 \\
\hline
\end{tabular}


Table 11: Pearson Correlation Analysis between Authoritative Parenting Style and Academic Procrastination $(\mathrm{N}=148)$

\begin{tabular}{lcc}
\hline Variable & \multicolumn{2}{c}{ Academic Procrastination } \\
\cline { 2 - 3 } & $\boldsymbol{r}$ & $\mathbf{p}$ \\
\hline Authoritative Parenting Style & 0.055 & 0.505 \\
\hline
\end{tabular}

Pearson Correlation analysis test also had been done on each of the three types of parenting style which are authoritative, authoritarian, and permissive to see its relationship with academic procrastination among the final students of Faculty of Human Ecology, Universiti Putra Malaysia. Based on Table 11, it shows that there is no significant relationship $(r=.055, \mathrm{p}=.505)$ between authoritative parenting style and academic procrastination among final year students of Faculty of Human Ecology.

Table 12: Pearson Correlation Analysis between Authoritarian Parenting Style and Academic Procrastination $(\mathrm{N}=148)$

\begin{tabular}{lcc}
\hline Variable & \multicolumn{2}{c}{ Academic Procrastination } \\
\cline { 2 - 3 } & $\boldsymbol{r}$ & $\mathbf{p}$ \\
\hline Authoritarian Parenting Style & 0.153 & 0.063 \\
\hline
\end{tabular}

As for authoritarian parenting style on Table 12, it shows that there is no significant relationship ( $r=$ $.153, \mathrm{p}=.063$ ) between authoritarian parenting style and academic procrastination among final year students of Faculty of Human Ecology.

Table 13: Pearson Correlation Analysis between Permissive Parenting Style and Academic Procrastination $(\mathrm{N}=148)$

\begin{tabular}{lcc}
\hline Variable & \multicolumn{2}{c}{ Academic Procrastination } \\
\cline { 2 - 3 } & $\boldsymbol{r}$ & $\mathbf{p}$ \\
\hline Permissive Parenting Style & 0.046 & 0.580 \\
\hline
\end{tabular}

Lastly, the hypothesis of the test for permissive parenting style on Table 13, it shows that there is no significant relationship $(r=.046, \mathrm{p}=.580)$ between permissive parenting style and academic procrastination among final year students of Faculty of Human Ecology. Therefore, the hypothesis is rejected.

Table 14: Mean Score of Each Parenting Style (N=148)

\begin{tabular}{lcc}
\hline \multicolumn{1}{c}{ Parenting Style } & Mean & Std. Deviation \\
\hline Authoritative & 3.7111 & 0.49685 \\
Permissive & 3.3922 & 0.44003 \\
Authoritarian & 3.2794 & 0.57026 \\
\hline
\end{tabular}

From the correlation which have been analysed as shown above, although all three (3) parenting styles did not show a significant relationship with academic procrastination, Table 14 shows that out of the three (3) types of parenting style, authoritative parenting style have the highest mean score which is 3.7111 followed by permissive parenting style with mean score of 3.3922 and 3.2794 for authoritarian parenting style. This shows that majority of the final year students in Faculty of Human Ecology had identified their parents' parenting style through the self-report questionnaire as authoritative style.

\section{Discussion}

Level of Academic Procrastination among final year students in Faculty of Human Ecology, Universiti Putra Malaysia 
The majority of final year students in faculty of Human Ecology, Universiti Putra Malaysia perceived a high level of academic procrastination while students with low level of academic procrastination are the minority. This indicates that university students especially those who are in their final year, experiencing procrastination in academic-related tasks although from the findings we can see the procrastination among the students are at different levels. This finding are in line with a study on procrastination which have been done by Bakar and Khan (2016) in Malaysia that found students do procrastinate although the level of seriousness in procrastinating are different. The academic tasks which students often need to deal with in the university are writing term assignment or term paper, studying for exams, keeping up with weekly assignments, tasks related to academic administrative, and also attendance tasks such as meeting with advisors or lecturers. Among the mentioned academic tasks, students tend to procrastinate in studying for exams the most compare to other tasks. Hussain and Sultan (2010) also had found previously that preparing for examination is one of the procrastination area that students regularly did. We could say that lack of preparation in exam caused by unclear planning. As mentioned by Al-Zoubi and Younes (2015), negative outcome will occur if they have intended to perform a repetitive action without planning. Therefore, we could say that students procrastinating are the negative outcome from their same bad behaviour such as not planning for studying earlier before the examination.

\section{Relationship between Gender differences and Academic Procrastination among final year students in Faculty of Human Ecology, Universiti Putra Malaysia.}

Regards on the first hypothesis of the study, there will be a significant relationship between gender differences and academic procrastination among final year students of Faculty of Human Ecology, Universiti Putra Malaysia. However, this study has proven that there is no significant relationship between the two variables although a study which was done by Mandap (2016) had found that there is a significance difference between the level of procrastination of male and female students. The possible reason for the indifferences in the results finding is may be because of the differences in terms of students' background apart from the reason that the number of male and female students is unbalanced. The study which was performed by Mandap (2016) was focusing on students of Bulacan State University, Philippines from different courses and were selected randomly while the present study are targeting on students from only one faculty, which is the Human Ecology Faculty specifically. In addition to that, differences in cultural background of the student country, Philippines and Malaysia may have different learning style regardless to their gender differences. However, the rejected hypothesis of the present study is supported by a research done by Sepehrian and Lotf (2011) which found that there was no significant relationship between the genders and academic procrastination. Although most of other researchers had found that academic procrastination are common among male students compare female students (Khan, 2014; Mandap, 2016; Balkis and Duru, 2017), however the result of this study shows the opposite which majority female students perceived a high level of academic procrastination while most of the male students perceived a low level of academic procrastination.

\section{Relationship between Parenting Styles and Academic Procrastination among final year students in Faculty of Human Ecology, Universiti Putra Malaysia.}

According to the third hypothesis of this study, there will be a significant relationship between parenting style and academic procrastination among final year students of Faculty of Human Ecology, Universiti Putra Malaysia. However, the result shows that there is no significant relationship between parenting styles in general. Besides that, the each parenting style which are authoritative, authoritarian and permissive also did not shows any significant relationship with academic procrastination although authoritative styles shows the highest mean score. In a study done by Loa (2012) also found that there is no relationship between authoritarian and permissive parenting style with academic procrastination. Contrary to the findings found by Javady and Mahmoudi (2015), the authoritative parenting style does not correlate with academic procrastination.

Here, we can see that the inconsistency in the outcomes of these two variables is because of the differences in targeted group of the respondents for the studies such Javady and Mahomoudi (2015) 
was focusing on girls students from high school while Loa (2012) focusing on undergraduate students may cause the variation in the research findings. To sum up the present study, it shows that the parenting styles of final year students of Faculty of Human Ecology has no effect on their procrastination in academic tasks as age can be considered the reasons for the uncorrelated relationship. Since the majority of the respondents are in the age of 23 which fall into the category of an early adulthood, there is a possibility for the students to feel that the parenting styles perceived by their parents does not influence their decisions in behaving in a certain way. This is because early adulthood is a transition phase in between adolescent and adulthood, where they are becoming more independent, to do things in their own way and to face the consequences of their action by themselves.

\section{Recommendation}

Based on the result of the present study, majority of the students perceived a high level of academic procrastination. Previous researchers have mentioned that academic procrastination can lead to some negative outcomes such as causes diseases, unhealthy sleeping habit, as well as affecting the students' morale such as smoking, drinking habit, and also plagiarism (Hussain \& Sultan, 2010). It also can causes the academic achievement of the students be affected. For that reason, few recommendations are proposed as below:

\section{Motivational programs are made compulsory for students with poor academic performance}

Motivational program is one of the common program which usually done in education institutes and can be in different form such as talk, forum, or camp. Therefore, by making motivational program compulsory for all students who experience a drop in CGPA can be one of the best alternative to help in improving the students' motivational level and give them motivations thus it will reduce the tendency towards procrastination. Previously, Universiti Teknologi Malaysia (UTM) had created a motivational program called "Kem Motivasi Pelajar Harapan PROPEMP for students of Electric and Electrical Engineering Faculty, UTM who obtained CGPA between 1.7 and 2.5. Based on the study done by Isa et al. (2008) on the program, it was found that $89 \%$ of the students agreed that the program was beneficial and effective. Therefore, there is a possibility for the motivational program will be successful.

\section{Motivational programs are made compulsory for all final year students}

Sirin (2011) had found that $31 \%$ of the seniors have been reported to have thought academic procrastination as a source of stress. In the senior years, there are many possible reasons for the senior students to procrastinate and one of the reasons is because of too much work (Hussain \& Sultan, 2010) such as final year project, other assignments and commitments. Apart from that, by selecting students with only decline in CGPA may not be fair as some of the students who obtained first class honour may also be procrastinating as well and this is why all students in their final year need to be involved in the motivational program.

\section{Parents need to be notified on student poor academic performance.}

Currently in Universiti Putra Malaysia (UPM), teaching assessment on lecturers by the students are compulsory in order for the lecturers to gain feedback from the students on the lecturer performance of each semester. With the same concept as the teaching assessment, it can be apply for students, where lecturers feel in the assessment on their student in terms of behaviour such as participation in class as well as level of procrastination. By considering the Procrastination Assessment Scale for Students (PASS) as part of the assessment can help the lecturer to evaluate the level of procrastination at different area of academic tasks. For students who score below the required standard of the assessment, the result can be shared to their parents via text message, email, or letter depending on the lecturer's preference. Form here, parents can adjust which parenting style to implement so that the students received more attention, motivated as well as helping them to not further procrastinate. Thus, this will 
also create engagement between the parents and their children as it was supported by Lucas (2010) in his article which he mentioned that good parent engagement leave a good outcome on student behaviour.

\section{Conclusion}

As a conclusion, academic procrastination is definitely a common behaviour that perceived by university students. Apart from that, parenting styles was found not effecting academic procrastination among the students. With the majority of the students are from the age of 22 to 27 years old which is categorised as early adulthood, parenting styles does not leave a big impact on them. As the phase of early adulthood is a transition phase from adolescent to adulthood which parenting styles perceived by their parents no longer influence their decisions and actions. The inconsistency of the outcome from previous and current study shows that it is difficult to measure the possible reasons for academic procrastination as it is possible for other underlying variables besides parenting styles to contribute in this behaviour.

\section{References}

Anspaugh, D.J., Diognan M. B., Anspaugh S. L. (2000). Developing Culture Promotion Programs. US. The Mc Graw - Hill. Companies, Inc.

Alkharusi, H., Aldhafri, S., Kazem, A., Alzubiadi, A., \& Al-Bahrani, M. (2011). Development and Validation of A Short Version of the Parental Authority Questionnaire. Social Behavior and Personality: An International Journal, 39, 1193-1208.

Al-Zoubi, S.M., \& Younes, M.A.B. (2015). Low Academic Achievement: Causes and Results. Theory and Practice in Language Studies, 5(11), 2262-2268.

Bakar, A.Z., \& Khan, U.M. (2016). Relationships between Self-Efficacy and the Academic Procrastination Behaviour among University Students in Malaysia: A General Perspective. Journal of Education and Learning, 10(3), 265-274.

Balkis, M., \& Duru, E. (2017). Gender Differences in the Relationship between Academic Procrastination, Satisfaction with Academic Procrastination, Satisfaction with Academic Life and Academic Performance, Electronic Journal of Research in Educational Psychology, 15(1), 105-125.

Baumrind, D. (1991). The Influence of Parentign Style on Adolescent Competence and Substance Use. Journal of Early Adolescence, 11(1), 56-95.

Buri, J. (1991). Parental authority questionnaire. Journal of Personality Assessment, 57, 110-119.

Cobb-Clark, D.A., Salamanca, N. \& Zhu, A. (2017). Parenting style as an investment in human development. IZA Discussion Paper 9689.

Darling, N., \& Steinberg, L. (1993). Parenting Style as Context: An Intergrative Model. American Psychological Association, Inc., 113(3), 487-496.

Ferrari, J.R., Johnson, J.L., \& McCown, W.G. (1995). Procrastination and Task Avoidance: Theory, Research, and Treatment. Spring Street, New York.

Hussain, I., \& Sultan, S. (2010). Analysis of procrastination among university students. Procedia Social and Behavior Sciences, 5, 1897-1904.

Jadidi, F., Mohammadkhan, S., \& Tajrishi, K.Z. (2011). Perfectionism and academic procrastination. Procedia Social and Behavioral Sciences, 30, 534-537.

Jago. R., Davison, K.K., Brockman, R., Page, A.S., Thompson, J.L., \& Fox, K.R. (2011). Parenting styles, parenting practices, and physical activity in 10- to 11-year olds. Preventive Medicine, 52, 44-47.

Javady, M.J., \& Mahmoudi, M. (2015). The relationship between perceived parenting styles and academic procrastination and fear of success. International Academic Journal of Humanities, 2(10), 31-49.

Kagan, M., Cakir, O., Ilhan, T., \& Kandemi, M. (2010). The explanation of the academic procrastination behaviour of university students with perfectionism, obsessive-compulsive and five factor personality traits. Procedia Social and Behavioral Sciences, 2, 2121-2125. 
Kandemir, M. (2014). Reasons of academic procrastination: self- regulation, academic self-efficacy, life satisfaction and demographics variables. Procedia Social and Behavioral Sciences, 152, 188 $-193$.

Khan, M.J. (2014). Academic Procrastination among Male and Female University and College Students. FWU Journal of Social Sciences, 8(2), 65-70.

Klassen, R.M., Krawchuk, L.L., \& Rajani, S. (2008). Academic procrastination of undergraduates: Low self-efficacy to self-regulate predicts higher levels of procrastination. Contemporary Educational Psychology, 33, 915-931.

Lee, M.Y. (2013). Academic Procrastination and Its Relationship with Parenting Styles and SelfEsteem among Undergraduate Students (Master's Thesis). Universiti Teknologi Malaysia, Malaysia.

Loa, R.I. (2012). Academic Procrastination and Parenting Styles in Psychology Students. Indonesian Psychological Journal, 27(4), 223-231.

Mahasneh, A.M., Bataineh, O.T., \& Al-Zoubi, Z.H. (2016). The Relationship Between Academic Procrastination and Parenting Styles Among Jordanian Undergraduate University Students. The Open Psychology Journal, 9, 25-34.

Mandap, C.M. (2016). Examining the Differences in Procrastination Tendencies among University Students. International Journal of Education and Research, 4(4), 431-436.

Moonaghi, H.K., \& Beydokhti, T.B. (2017). Academic Procrastination and Its Characteristics: A Narrative Review. Future of Medical Education Journal, 43-50.

Onwuegbuzie, A.J. (2004). Academic procrastination and statistics anxiety. Assessment \& Evaluation in Higher Education, 29(1).

Park, S.W. (2008). Self-Regulation of Academic Procrastinators: A Mixed Methods Study (Master's Thesis). The Pennsylvania State University, USA.

Pychyl, T.A., Coplan, R.J., \& Reid, P.A.M. (2002). Parenting and procrastination: gender differences in the relations between procrastination, parenting style and self-worth in early adolescence. Personality and Individual Differences, 33, 271-285.

Rabin, L.A., Fogel, J., \& Nutter-Upham, K.E. (2011). Academic procrastination in college students: The role of self-reported executive function. Journal of Clinical and Experimental Neuropsychology, 33(3), 344-357.

Ribeiro, L.L. (2009). Construction Validation of a Four Parenting Styles Scale. (Master's Thesis). Humboldt State University.

Sepehrian, F., \& Lotf, J.J. (2011). The Effects of Coping Styles and Gender on Academic Procrastination among University Students. Journal of Basic and Applied Scientific Research, 1(12), 2987-2993.

Sirin, E.F. (2011). Academic procrastination among undergraduates attending school of physical education and sports: Role of general procrastination, academic motivation and academic selfefficacy. Educational Research and Reviews, 6(5), 447-455.

Solomon, L.J. \& Rothblum, E.D. (1984). Academic Procrastination: Frequency and CognitiveBehavioral Correlates. Journal of Counseling Psychology, 31(4), 503-509.

Solomon, L. J., \& Rothblum, E. D. (1994). Procrastination Assessment Scale-Students (PASS). In J. Fischer, \& K. Corcoran (Eds.), Measures for clinical practice (pp. 446-452). New York, NY: The Free Press.

Spera, C. (2005). A Review of the Relationship Among Parenting Practices, Parenting Styles, and Adolescent School Achievement. Educational Psychology Review, 17(2), 125-146.

Steel, P. (2007). The Nature of Procrastination: A Meta-Analytic and Theoretical Review of Quintessential Self-Regulatory Failure. Psychological Bulletin, 133(1), 65-94.

Zakeri, H., Esfahani, B.N., \& Razmjoee, M. (2013). Parenting Styles and Academic Procrastination. Procedia Social and Behavioral Sciences, 84, 57-60. 